\title{
The USGS Role in Mapping the Nation's Submerged Lands
}

\section{The Nation's Submerged Lands}

The seabed provides habitat for a diverse marine life having commercial, recreational, and intrinsic value. The habitat value of the seabed is largely a function of the geological structure and related geological, biological, oceanologic, and geochemical processes. Of equal importance, the nation's submerged lands contain energy and mineral resources and are utilized for the siting of offshore infrastructure and waste disposal. Seabed character and processes influence the safety and viability of offshore operations. Seabed and subseabed characterization is a prerequisite for the assessment, protection, and utilization of both living and non-living marine resources (fig. 1). A comprehensive program to characterize and understand the nation's submerged lands requires scientific expertise in the fields of geology, biology, hydrography, and oceanography.

\section{USGS Leadership in Geologic Mapping}

The U.S. Geological Survey (USGS) has long experience as the Federal agency charged with conducting geologic research and mapping in both coastal and offshore regions. The USGS Coastal and Marine Geology Program (CMGP) leads the nation in expertise related to characterization of seabed and subseabed geology, geological processes, seabed dynamics, and (in collaboration with the National Oceanic and Atmospheric Administration (NOAA) and international partners) habitat geoscience. Numerous USGS studies show that sea-floor geology and processes determine the character and distribution of biological habitats, control coastal evolution, influence the coastal response to storm events and human alterations, and determine the occurrence and concentration of natural resources.

\section{Regional and Topical Studies}

The CMGP uses research and mapping expertise to conduct regional and topical studies that address issues on the nation's submerged lands related to hazards, natural resources, environmental impacts, environmental change, and engineering projects. The CMGP collaborates with national and international agencies to develop new approaches for collecting and interpreting seabed imagery, mapping shallow stratigraphy, and gathering related data relevant to habitat determination, resource assessments, and the understanding of vulnerability and change.

Hazards - Studies address the impacts of earthquakes, tsunamis, and submarine and coastal landslides, as well as coastal change caused by erosion, storms, sea-level rise, and land subsidence, and are the basis for national assessments of vulnerability and change.
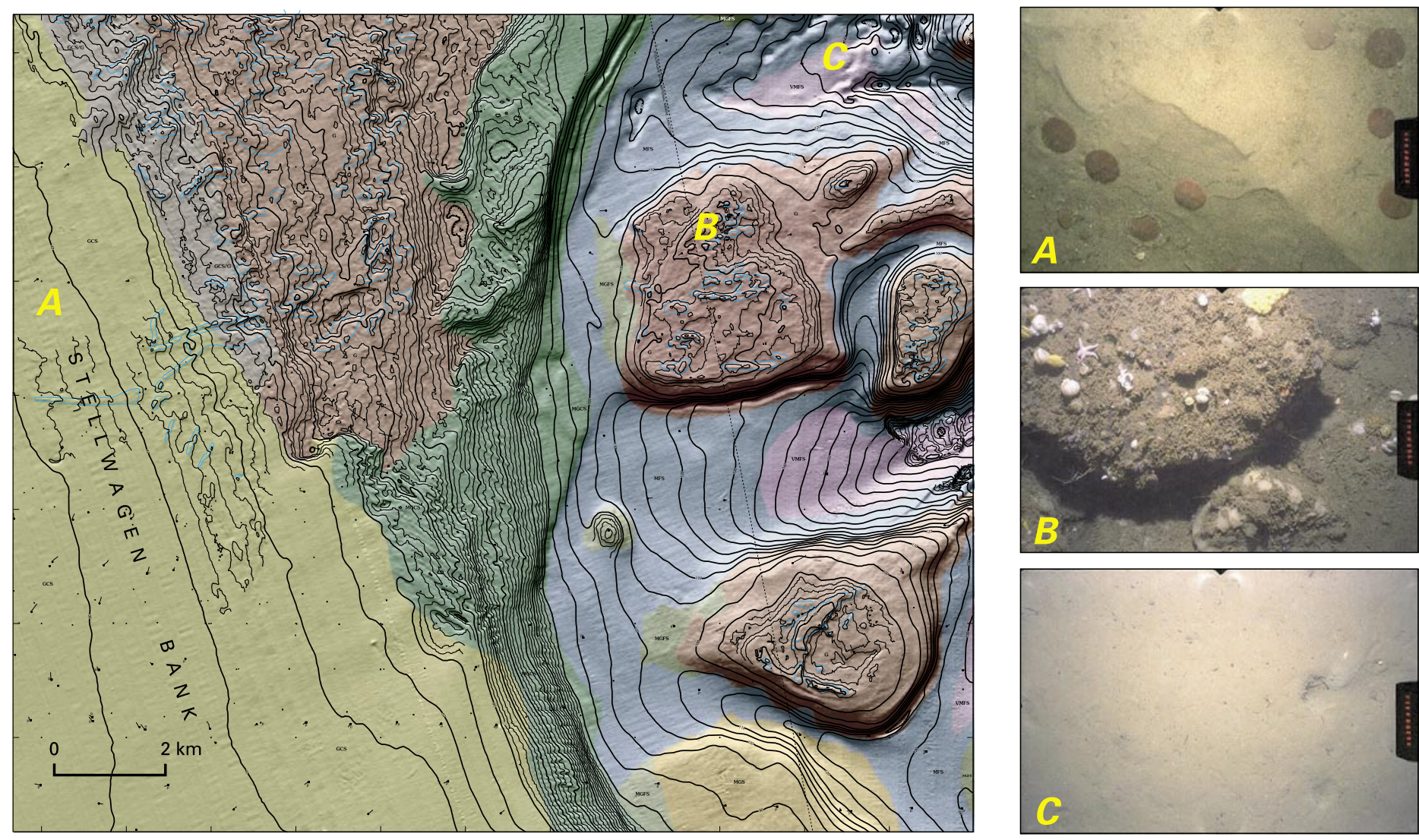

Figure 1. Interpretive map of the southeastern part of Stellwagen Bank and adjacent small banks, about 80 kilometers east of Boston, Mass. Map shows shaded-relief imagery of the seabed, detailed topography (1-meter contours) of the most rugged areas, and the distribution of seabed habitats that range from smooth to rough and from muddy (purple, blue) to sandy (green, yellow) to gravelly (gray and reddish brown). Map area is 220 square kilometers; water depths range from 35 meters in the west to 180 meters in the east. Photographs show habitats supporting different kinds of marine life. A, Storm-generated coarse sand ripples with sand dollars (6 centimeters diameter); depth 39 meters. $\boldsymbol{B}$, Boulders encrusted with sponges, sea stars, brachiopods, and tunicates; small boulder is 30 centimeters wide; depth 89 meters. C, Smooth, muddy sand seabed with fish or crab burrows; depth 137 meters. 
Natural Resources-Studies of the occurrence and distribution of sand and gravel, other mineral resources, methane gas hydrate, and ground water lead to assessments of resource potential and of impacts of resource utilization.

Environment-Studies of seabed environments provide the geological basis for understanding physical processes in healthy and declining lacustrine, wetland, estuarine, marine, benthic, and coral ecosystems. Areas of habitat geoscience research include the following:

- Development and application of analytical methods and "ground-truth" approaches required to interpret digital sea-floor imagery

- Development of geology-based methods to classify and inventory seabed types and habitats; documentation of how species distributions are influenced by the geological character and processes that affect habitats

- Investigation of geochemical cycling of contaminants impacting ecosystem and human health; development of techniques to assess and model coastal ground-water resources and the influence of ground water on submerged habitats

- Development of physical, geochemical, and coupled physical-ecological models to predict (1) ocean circulation; (2) sediment movement; (3) effects of currents on seabed morphology, materials, and organisms; (4) drift patterns of plankton and of eggs and larvae of fishery species; and (5) transport and ecosystem impacts of contaminants and ground water.

\section{Comprehensive Seabed Mapping}

The CMGP provides expertise essential for the development of a comprehensive seabed mapping program by (1) pursuing the research topics discussed above, (2) developing new survey techniques, (3) providing geological analyses of seabed imagery and subseabed data, and (4) producing interpretive maps that show the distribution of sediments, ground water, contaminants, and seabed habitats, as well as sediment transport processes and the structure and depositional history of the seabed (fig. 2).
CMGP can support enhanced mapping programs by developing new approaches to mapping, by testing new concepts for image and data interpretation, and by coordinating prioritized mapping activities to meet longterm research and immediate management goals. Effective mapping programs will require USGS expertise and partnerships with government, industry, and academia in order to meet the objectives of management and regulatory agencies and to ensure that the breadth of research capabilities reflects the diverse applications that are required of seabed maps.

For more information, please contact:

Bill Schwab

U.S. Geological Survey

Woods Hole Science Center

384 Woods Hole Road

Woods Hole, MA 02543-1598

Telephone: (508) 457-2211

E-mail: bschwab@usgs.gov

John Haines

U.S. Geological Survey

Mail Stop 915B

National Center

Reston, VA 20192-0002

Telephone: (703) 648-6422

E-mail: jhaines@usgs.gov

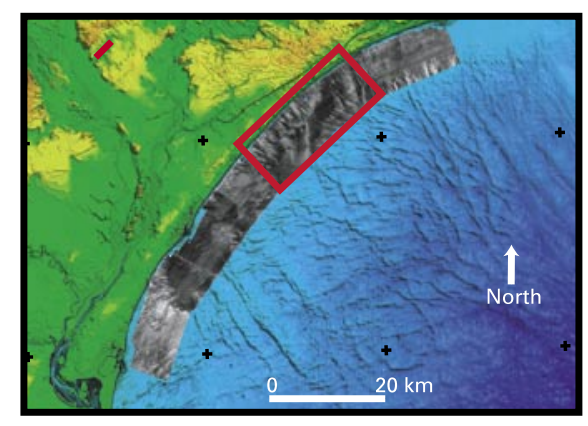

\section{3-D Perspective View of Area Outlined in Red on Map at Left}
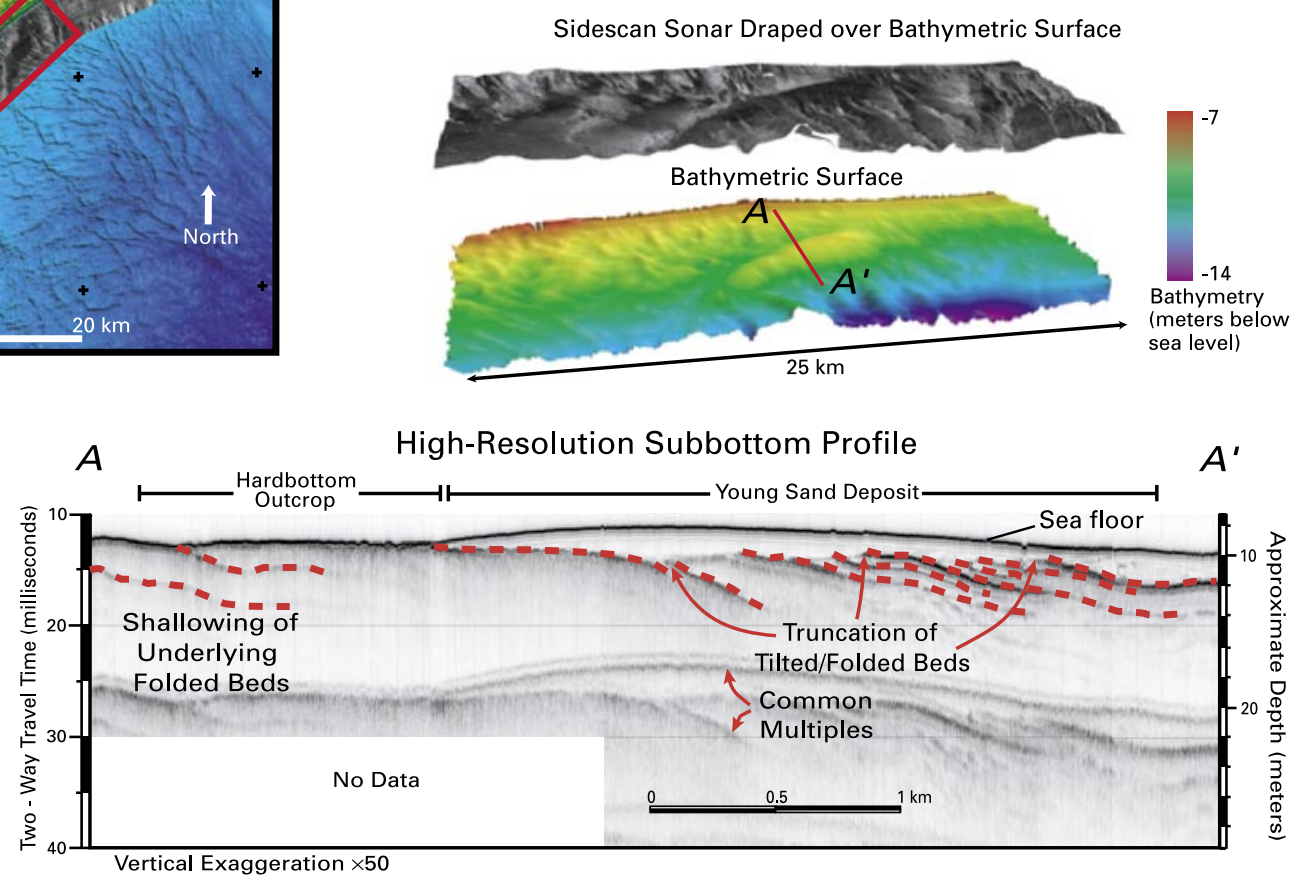

Figure 2. Seabed map, three-dimensional sidescan-sonar perspective images, and subbottom profile of the sea floor off Myrtle Beach, S.C. These images were produced aboard a research vessel as part of an ongoing investigation of coastal erosion hazards. Top right, The color image shows bathymetry. The black and white image above it combines bathymetry and seabed backscatter (the intensity of sound reflected from the sea floor); gray tones represent seabed types and range from hard (light gray) to soft (dark gray). Bottom, Subbottom profile A-A' illustrates the recent history of the sea floor and shows the accumulation of a young sand deposit over older, harder, folded beds. 